TUNISIA Stifled for decades, scientists welcome the revolution $\mathbf{p . 4 5 3}$
SOLAR PHYSICS High hopes for the Glory probe's mission to watch the Sun $\mathbf{p . 4 5 7}$
NEUROSCIENCE Picturing

Alzheimer's plaques in the living brain $\mathbf{p . 4 5 8}$
CHINA A maverick plots a clear course for marine research $\mathbf{p . 4 6 0}$

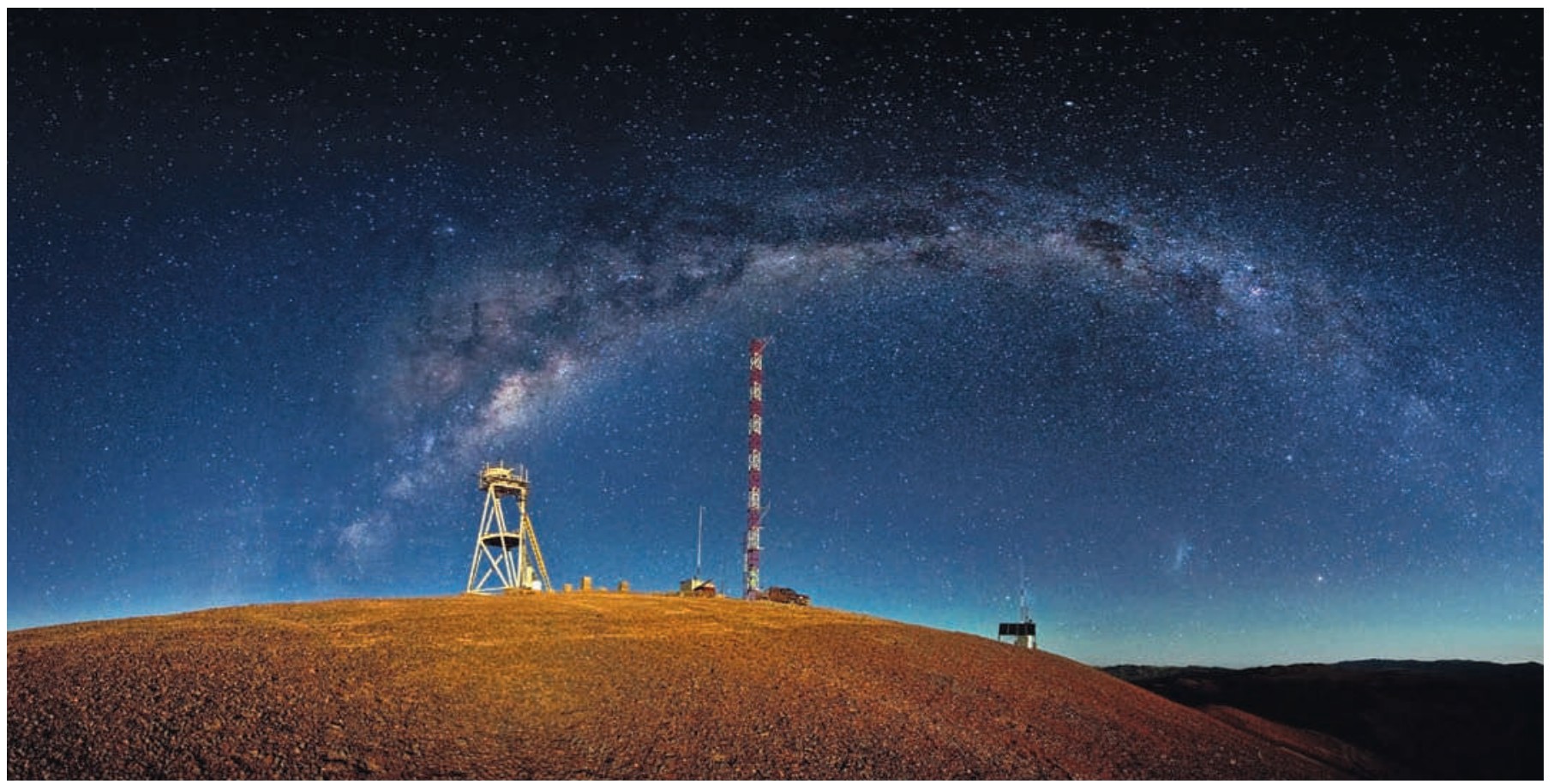

Site tests suggest that the superlative observing conditions on Cerro Armazones make it an ideal location for the European Extremely Large Telescope.

\title{
Brazil ignites telescope race
}

\section{Deal boosts Europe's bid to build world's biggest observatory, as US groups compete for funds.}

\section{BY ADAM MANN}

$\mathrm{T}$ To astronomers, Cerro Armazones in Chile's Atacama Desert practically screams for an observatory. Above it is the same dry, stable air that gives the Very Large Telescope (VLT), 20 kilometres away at Cerro Paranal (see map), one of the world's best views of the heavens. But at 3,064 metres, more than 400 metres higher than Paranal, Armazones should make an even better perch for an extraordinary telescope.

The mountain may not have much longer to wait. On 29 December, Brazil announced its intention to join the European Southern Observatory (ESO), which operates the VLT among other sites in Chile. If ratified by Brazil's parliament, the move will make it the consortium's fifteenth, and first non-European, member. It also significantly improves the odds that the European Extremely Large Telescope (E-ELT), an optical behemoth that would be the world's largest telescope and possibly the most important astronomical tool of the century, will be built on the summit of Armazones, with construction to begin as soon as next year.

"We have the site. We have the design. The addition of Brazil puts the whole funding scenario on a much sounder footing," says Tim de Zeeuw, director-general of ESO, which is headquartered in Garching, Germany.

The deal will give Brazil's astronomers access to ESO's facilities and put the country's burgeoning high-tech sector in a position to bid competitively on building components for the

\section{$\rightarrow$ NATURE.COM}

For more on next-generation telescopes: go.nature.com/lpcyol
E-ELT. In return, Brazil will contribute about $€ 300$ million (US\$400 million) to ESO over ten years, including a $€ 130$-million entry fee. That is enough to tip the scales in favour of the E-ELT being built and to cement ESO's status as the world's leading astronomical research entity. ESO had already selected Armazones as the preferred site for the E-ELT next-generation observatory, which would have a segmented main mirror that is a staggering 42 metres across - giving it 15 times more light-gathering power than the largest telescopes in use today. But until now, it has not been clear whether the organization would secure the estimated $€ 1$ billion it needs to make the E-ELT a reality.

The news increases pressure on two US-led efforts of comparable scale: the Thirty Meter Telescope (TMT) project, which also considered Armazones but instead opted for the 
- advantages of a US location on Mauna Kea in Hawaii, and the Giant Magellan Telescope (GMT), a 24.5-metre instrument planned on the summit of Cerro Las Campanas in Chile. Both are backed by a broad collaboration of US universities and international partners, and are aiming for first light around 2019, about the same time as the E-ELT.

Last year, the US astronomical community's Astro2010 decadal review recommended that the National Science Foundation (NSF) support a giant new observatory. But with resources constrained, the panel said the NSF must choose between the two US-led telescopes.

\section{GRANDER DESIGN}

Both the E-ELT and the TMT are designed along the lines of the two 10-metre Keck Telescopes in Hawaii, but on a grander scale. Their primary mirrors will consist of hundreds of 1.45-metre hexagonal mirrors, the position of which can be controlled individually to optimize image quality. By contrast, the GMT will be composed of six 8.4-metre mirrors arranged around a seventh, central mirror of the same size (see 'Big eyes on the sky').

The scientific case for such enormous instruments is strong, says Ray Carlberg, an astrophysicist at the University of Toronto, Canada, and the Canadian project director of the TMT. They will see to the edge of the visible Universe and discern the formation of the earliest stars, galaxies and black holes. Closer to home, they will image planets in orbit around other stars and probe their atmospheres for constituents that might indicate the presence of life. Any country without access to such a powerful instrument will be at a great disadvantage compared with the rest of the astronomical community, says Carlberg.

Because of their size and cost, such projects require more resources than any single nation can provide. In ESO's case, Brazil's cost of entry is matched by a total of $€ 300$ million already committed by the 14 European members.
ESO has also asked members for a further "extraordinary contribution" of $€ 400$ million, which should cover the remaining construction costs of the E-ELT, says de Zeeuw. Despite austerity measures, he hopes that the European states will formally agree to provide the extra funding by the middle of this year.

Roger Davies, an astrophysicist at the University of Oxford, UK, and chair of the E-ELT standing review committee, says that Brazil's entry greatly improves the odds that the remaining funds will fall into place. If that happens, ESO's governing council could approve the E-ELT by September, with construction to begin early next year.

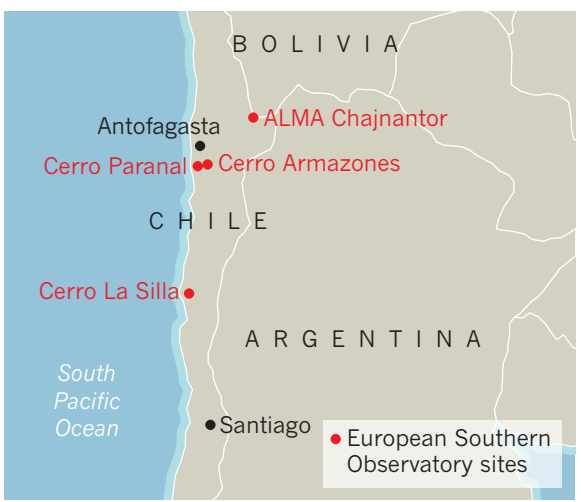

For the TMT and GMT, by contrast, momentum has slowed. The decadal review, which recommended that the NSF cover $25 \%$ of the cost of one project, urged the agency to make the decision between the two projects "as soon as possible". Researchers are concerned that a prolonged period of uncertainty could drive away other partners.

An informed decision cannot be made without analysing how such a large investment will shape the scientific community in the years to come, says James Ulvestad, division director for astronomical sciences at the NSF. "It's predicting the future," he says. "You have to evaluate where science will be - not today, not next month, but in ten years." Ulvestad says the agency should be ready to conduct a review of proposals from the GMT and TMT by mid2011, with a decision to follow by December.

Another complication is that the decadal review lists building the Large Synoptic Sky Telescope (LSST), an 8.4-metre survey instrument that will image wide areas of the sky, as a higher immediate priority than the GMT or TMT. Adhering to this would mean that the NSF would not be free to commit construction funding to other projects before the LSST is built, which could be late in the decade - long after the GMT and TMT project teams hope to be well on the way towards completion.

Both projects are making contingency plans in case federal funding does not materialize. "It certainly would be helpful," says GMT director Patrick McCarthy, but the GMT could still go ahead without NSF support, he says, as its international partners, Australia and South Korea, have made their funding commitments.

Similarly, Edward Stone, vice-chair of the TMT's board of directors, says that the TMT aims to get started as planned, "and that will be if the NSF joins or not". But the TMT could soon face a setback. A draft planning document circulated this month by the Canadian astronomical community recommends that Canada pull out of the TMT and seek membership of ESO if, by 2014, the TMT has fallen significantly behind the E-ELT.

The recommendation is a reminder of the high stakes in the rivalry, as observational astronomy shifts from an era in which a dozen or so major observatories represented the leading edge of the field to a time when just two or three will do so. "People are realizing it will be devastating to be left behind," says Carlberg.

By joining ESO, Brazil, which also considered the GMT and TMT, has apparently decided it will not be left behind. The coming year will determine who else may be in or out of astronomy's next great round of cosmic exploration.

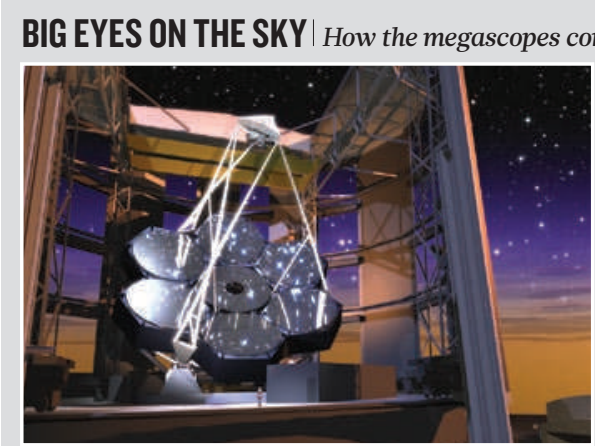

PROJECT NAME: Giant Magellan Telescope SELECTED SITE: Cerro Las Campanas, Chile DIAMETER OF MIRROR ARRAY: 24.5 metres PARTNERS: United States, Australia, South Korea ESTIMATED COST: US $\$ 700$ million PROJECTED CONSTRUCTION PERIOD: 2012-20* * Subject to funding

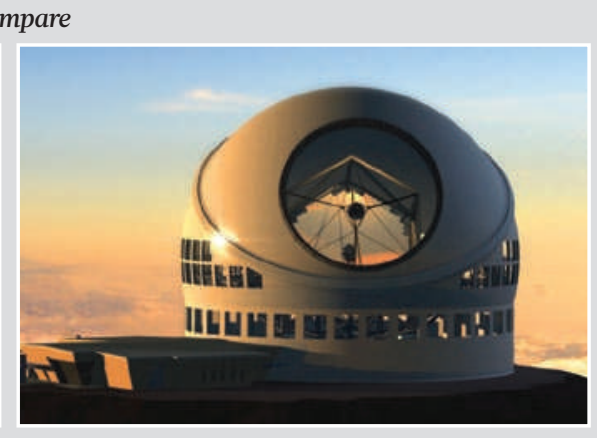

PROJECT NAME: Thirty Meter Telescope SELECTED SITE: Mauna Kea, Hawaii DIAMETER OF MIRROR ARRAY: 30 metres PARTNERS: United States, Canada, Japan, India, China ESTIMATED COST: US\$1 billion PROJECTED CONSTRUCTION PERIOD: 2012-19* * Subject to funding

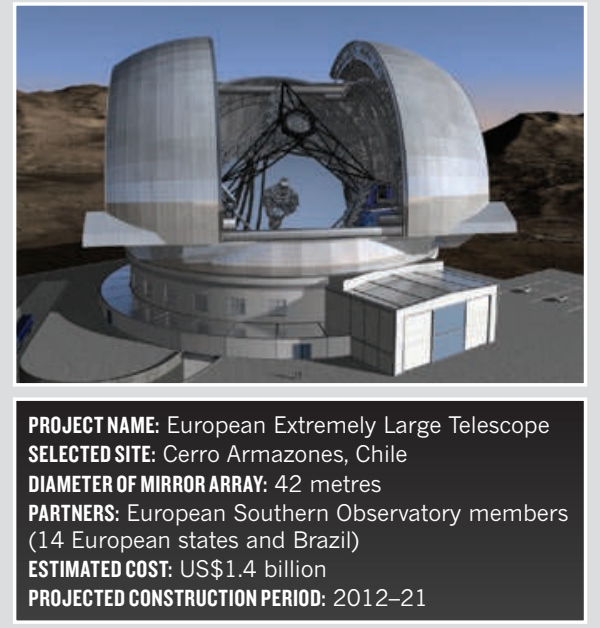

